\title{
Effects of Three Types of Control Devices on Closed-Type Supersonic Cavity Flows
}

\author{
By Jianbo ZHANG, Etsuo MoRISHITA, Takeo OKUNUKI and Hiroshi ITOH \\ Department of Aeronautics and Astronautics, The University of Tokyo, Tokyo, Japan
}

(Received August 22nd, 2002)

\begin{abstract}
Three types of devices were tested for their effects in reducing the strong adverse pressure gradient in a closed-type cavity with a depth of $8 \mathrm{~mm}$ and length-to-depth ratio of 15 . The first type of control device consisted of embedding arrays of tubes longitudinally along the two sides of the cavity. It sought to move the high-pressure air at the recompression wake to the separation wake by creating a passage. The second type of control device consisted of installing a baffle plate laterally near the shock impingement line or the mid-part of the cavity floor. It aimed at changing the wave structure of the cavity flow through interfering with the reattaching or reattached boundary layer. With the third type of control device, we tried to increase the base pressure by supplementing external fluid with downstream blowing through sideholes along a lateral tube placed at the front corner of the cavity. Of the three types of control devices, the installation of tubes along the two sidewalls of the cavity was found to be the most effective in reducing adverse pressure gradient along the cavity centerline. Of the four combinations of plates installed laterally on the cavity floor, the 4-mm-high plate installed near the middle of the cavity was found to be the most effective. The relative ineffectiveness of downstream blowing near the cavity front corner is believed to be a result of the low blowing rate.
\end{abstract}

Key Words: Cavity Flows, Closed-Type, Control

\section{Introduction}

Compressible flows over cavity-like geometries such as grooves, wheel wells, and cutouts, etc., occur widely in aerospace and aeronautical vehicles. The flow field features boundary layer separation, shear layer instability, vortex flow, acoustics radiation, shock/expansion wave and shockboundary-layer interactions, and self-sustained pressure oscillations. The co-presence of and interaction among these features in such a simple configuration and their potential hazardous effects on the performance, integrity and stability of the vehicles present a challenging problem and have stimulated extensive experimental, analytical, and computational investigations over the years.

Past research $^{1,2)}$ has established that the defining parameter for such flows is their length-to-depth ratio $(L / D)$. Closed flows occur for cavities with $L / D$ greater than 13 . The pressure distribution along the cavity floor centerline features a strong adverse gradient, resulting in large pressure drag for the vehicles. Open flows occur for cavities with $L / D$ less than 10 . The flow fields feature strong pressure oscillations. Noise radiation, structural fatigue, and excessive heat transfer at the cavity trailing edge are problems associated with open cavity flows. For $L / D$ from 10 to 13 , transitional cavity flow occurs.

As the understanding of cavity flows advances, efforts have also been taken to search for ways of controlling the cavity flow fields. By varying the rear wall from rectangular to circular and to ramp, Charwat et al. ${ }^{1)}$ investigated the ef-

(c) 2003 The Japan Society for Aeronautical and Space Sciences fect of downstream cavity edge geometry on compressible, closed-type cavity flow. They found that the geometry of the recompression step did not essentially modify the pressure distribution in the cavity, and the length $L$ of the cavity should be defined to the reattachment of the free-streamline.

For incompressible, open-type cavity flows, Pereira and Sousa $^{3)}$ found that different downstream cavity edge geometry (sharp, nose-shaped, and round) did not alter the corresponding value of the Strouhal number, despite the fact that the recirculating flowfield inside the cavity was markedly influenced by the downstream corner geometrical detail. Attenuation of the fluctuation peak magnitudes was observed for nose-shaped impingement edges.

After trying various ways to affect the oscillation process in open cavity flow, Heller and Bliss ${ }^{4)}$ concluded that the introduction of vorticity into the shear layer through spoilers installed ahead of the cavity leading edge, and provision of a slanted trailing edge bulkhead had a stabilizing effect on the external free shear layer and helped to reduce oscillating amplitudes. No oscillation amplitude reduction was observed by the forced entrainment of boundary layer fluid into the cavity at the leading edge, by tilting the leading- and /or trailing-edge bulkheads, by implementation of an upstream "spoiler cavity," or by cavity internal transverse spoilers and baffles.

The effect of a passive-venting system, consisting of a porous floor with a vent chamber beneath it, was investigated by Wilcox. ${ }^{5)}$ This arrangement, allowing high-pressure air from the rear of the cavity to vent to the forward part of the cavity, was found to be extremely effective in modifying 
the flow field over a cavity with closed-type flow at supersonic speeds. The type of the flow field changed from that of closed to that of transitional, with the drag reduced by a factor of approximately 3. Covering the porosity near the cavity midlength with tape did not significantly reduce the effectiveness.

In addition to experimental research, numerical simulation has also been employed to examine various ideas for their effects on cavity flows. The effect of a small jet, placed within an open-type cavity just below the front lip, was examined by Lamp and Chokani ${ }^{6)}$ using two-dimensional time-accurate Navier-Stokes simulation with a BaldwinLomax turbulence model. The force of the jet on the shear layer was found to be effective in reducing large pressure oscillations. The effectiveness of the suppression was found to strongly depend on the amplitude and frequency of the jet and weakly depend on the phase angle and duty cycle of the jet. Zhang et al. ${ }^{7}$ investigated the effects of leading edge compression ramps, expansion surfaces and mass injection on supersonic shallow cavity flow oscillations through solutions of Short-time Reynolds-Averaged Navier-Stokes equations with the turbulence modeled by a two-equation $\kappa-\omega$ model.

The focus of the present work is the control of supersonic closed-type cavity flow that occurs for cavities with $L / D$ values greater than approximately 13 . The schlieren photographs and sketch of the wave structures and flow field in the centerline plane of a typical closed-type cavity flow are shown in Fig. 1. The surface flow patterns are shown in Fig. 2. The flow separates at the front edge of the cavity, reattaches at some point along the cavity floor, and separates again before reaching the rear cavity face. This flow produces a mean static-pressure distribution with low pressure in the front region, a plateau in the attached region, and high pressure in the aft region. Impingement and exit shocks are
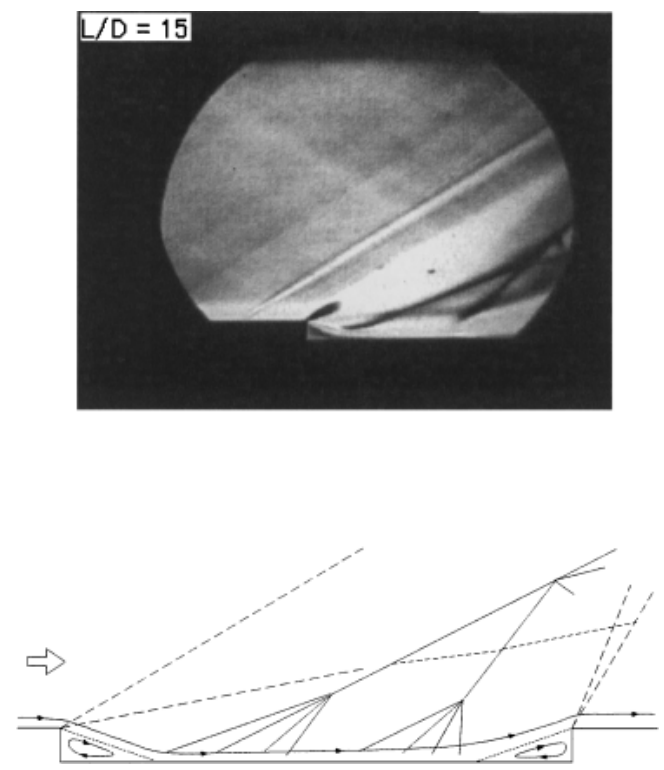

Fig. 1. Schlieren photograph, wave structures and flow field in the centerline plane of a closed-type cavity.

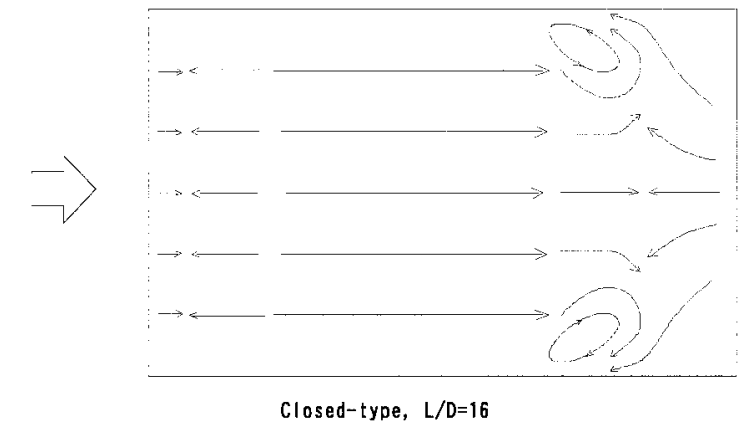

Fig. 2. Surface flow patterns for a typical closed-type cavity.

observed above the cavity floor.

The strong pressure gradient in closed-type cavity flow is undesirable in that it produces a nose-up pitching moment during the separation of store and that it increases the drag of the vehicle significantly. It has been found ${ }^{5)}$ that the cavity experiences an abrupt rise in drag as the flow changes from transitional to closed-type. Therefore, it is highly desirable to find ways to change the flow of a cavity from closed-type to transitional. In the mean time, no self-sustained oscillation of open-type cavity flow should occur or be significant as that would lead to structural fatigue. Furthermore, for a control device to be practical, it should be both effective and simple, not incurring excessive weight or drag penalty, and not reducing usable cavity volume significantly. The present work seeks to investigate three types of devices for their effects in reducing the strong adverse pressure gradient associated with closed-type cavity flow based on understanding the mechanism for change in cavity flow types as their $L / D$ changes.

It was found in the first author's Ph. D. work ${ }^{8)}$ that the freedom of the backflow inside the cavity is the key factor in shifting the mass balance at the front corner of the cavity, thereby determining the change of cavity flow type as its length-to-depth $(L / D)$ ratio increases. When the backflow is completely blocked, the cavity flow settles to a stable closedtype. The first type of control device tested is arrays of tubes embedded longitudinally along the two sides of the cavity. The idea is to facilitate the backflow by providing a passage for the high-pressure fluid at the rear part of the cavity to vent into the low-pressure front region of the cavity.

It was also found ${ }^{8)}$ that closed-type cavity flow changes to that of transitional-type as the $L / D$ decreases when the reattached boundary layer separates under the increased adverse pressure gradient when the front expansion wake and the rear recompression wake approach each other. The second device tested is a baffle plate laterally installed near the shock impingement line or the mid-part of the cavity floor. It is hoped that by interfering with the reattaching or reattached boundary layer and forcing it to separate, the wave structure of the cavity flow might change.

The third device tested is external fluid addition by downstream blowing through side-holes along a lateral tube placed at the front corner of the cavity. External fluid addi- 


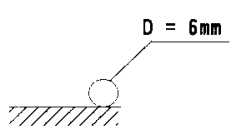

$A-A$

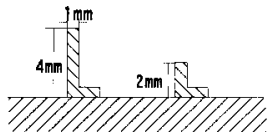

B-B

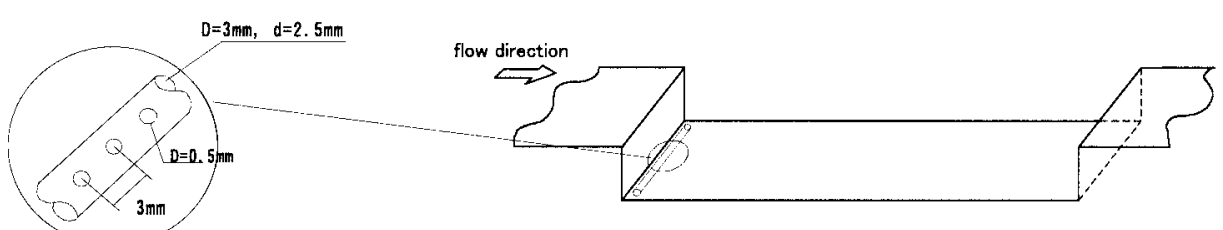

Close-up

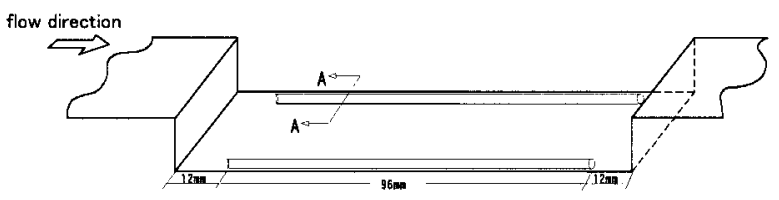

(1) Longitudinal tubes along the side walls of wind tunnel

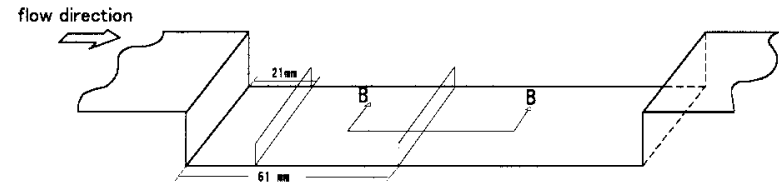

(2) Front and rear plate locations

(3) Lateral blowing tube at the front corner

Fig. 3. Schematic of cavity models with control device installed.

tion near the front corner will certainly delay the change of flow to the closed-type (elevating the critical length-to-depth ratio). However, it is unclear how external fluid addition will affect cavity flow when its $L / D$ is much larger than the critical value.

\section{Test Apparatus, Instrumentation and Models}

The tests were conducted in the supersonic wind tunnel of the Department of Aeronautics and Astronautics, The University of Tokyo. The test section has a rectangular cross section of 80 by $140 \mathrm{~mm}^{2}{ }^{2}$ A nozzle designed for Mach 2 was used in the current work. The boundary layer just upstream of the position where cavities are to be installed was measured and judged to be turbulent, its thickness was estimated to be about $8 \mathrm{~mm}$.

Two-dimensional (2D) rectangular cavity models, with a depth of $8 \mathrm{~mm}$ and values of $L / D$ equal to 15 , with and without control devices installed, were tested. The model is instrumented with 24 pressure orifices, $0.5 \mathrm{~mm}$ in diameter, along the floor centerline. The installation of control devices in the cavity is shown in Fig. 3.

The total temperature and total pressure in the settling chamber were measured with a thermo-couple and Pitot tube, respectively. The static pressures along the cavity walls were connected with a scanning valve. Three unsteady pressure orifices were opened near the centerline of the cavity floor, with the distance from the front wall being 15, 30, and $75 \mathrm{~mm}$, respectively. The pressure transducers were products of Kulite Semiconductor. All the pressure transducers were referenced to atmospheric pressure, the value of which was read from a pressure meter each time before a test run.
The electronic signals from the thermo-couple and pressure transducers, amplified with voltage amplifiers, were input to a computer through an $\mathrm{A} / \mathrm{D}$ converter. The $\mathrm{A} / \mathrm{D}$ converter had a capacity of 12 bits and was set to work in a range of $\pm 10 \mathrm{~V}$. The maximum sampling rate of the converter was $200 \mathrm{MHz}$. The thermo-couple was calibrated against a thermometer. The static pressure transducers were calibrated against a mercury U-tube manometer. The total pressure transducers were calibrated against a pressure gauge, which had a range of $5 \mathrm{~kg} / \mathrm{cm}^{2}$ and an error of $0.1 \%$ of the reading. The calibrations were repeated several times during the entire experiment to account for variations in atmospheric temperature and humidity.

The freestream Mach number, calculated from freestream total pressure and static pressure at the wind tunnel wall opposite to the cavity using isentropic relation, had a value of 1.94, and the Reynolds number per unit meter was $4.2 \times 10^{7}$. Pressure coefficients at the cavity walls were calculated as follows:

$$
C_{\mathrm{p}}=\frac{2}{\gamma M_{\infty}^{2}}\left(\frac{p}{p_{\infty}}-1\right)
$$

Schlieren visualization was taken during all the test runs. Oil flow visualizations using oil (500CS) mixed with $\mathrm{TiO}_{2}$ were conducted.

\section{Test Results and Discussion}

\subsection{Tubes along two sidewalls of cavity}

Plastic tubes, $96 \mathrm{~mm}$ long and with a diameter of $6 \mathrm{~mm}$, were embedded longitudinally along the two sides of the cavity. Two cases were tested. In the first case, three tubes were patched together and pasted on the floor along each 
sidewall of the cavity. In the second case, only one tube was pasted on each side. The tubes were placed near the midportion of the cavity, with one end opening to the front part of the cavity and the other end to the rear part. It was expected that by creating a passage for the high-pressure air in the recompression wake to vent into the low-pressure separation wake, the pressure at the front region would increase, the expansion of the main flow at the leading edge would be weakened, and the flow would change to that of the transitional type.

Figure 4 compares the pressure coefficient distribution in the cavity having tubes installed (the lines with open circle or cross markers) with that of the basic cavity (the line with dot markers). The left and right panels correspond to the three tubes and one tube at each side, respectively. Both cases were found to be effective in changing the cavity flow to the
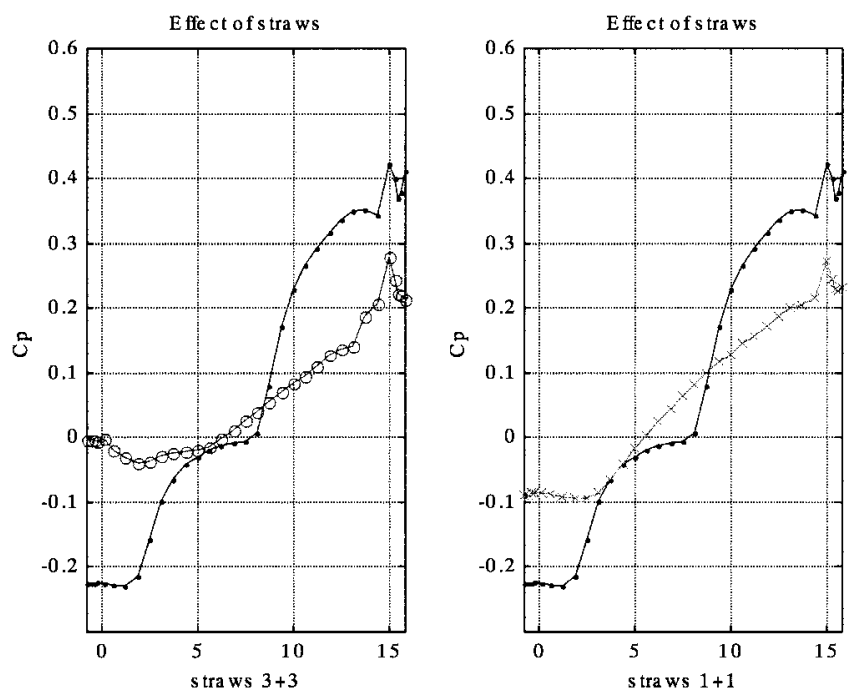

Fig. 4. Effects of venting tubes on pressure distribution.
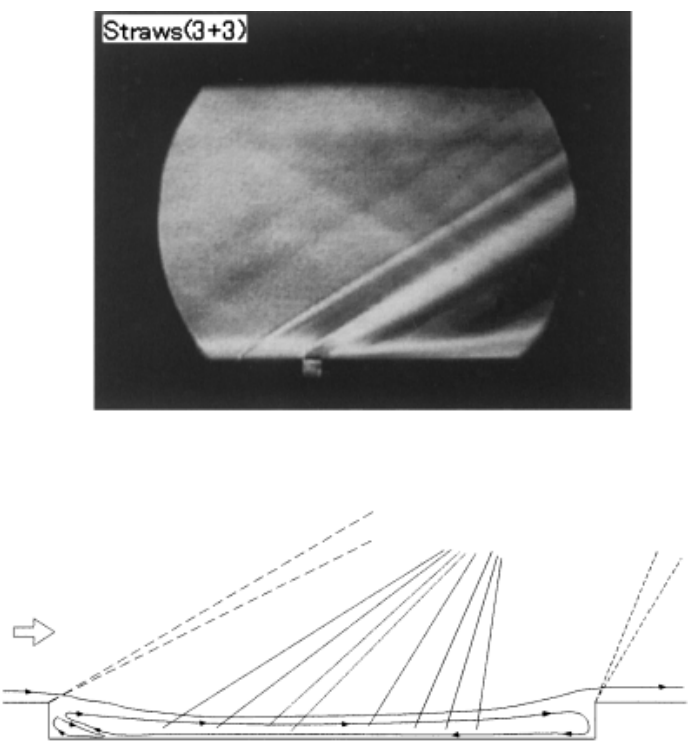

Fig. 5. Schlieren photograph and sketch of the wave structures and flow field in the centerline plane of a closed-type cavity with venting tubes.

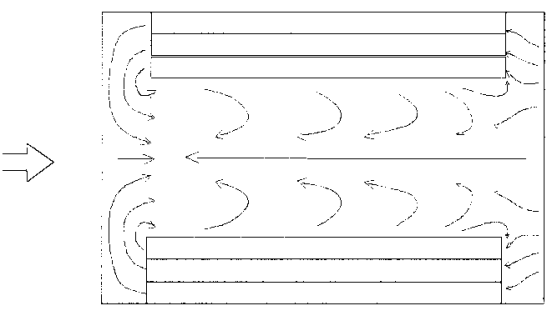

three tubes along each side

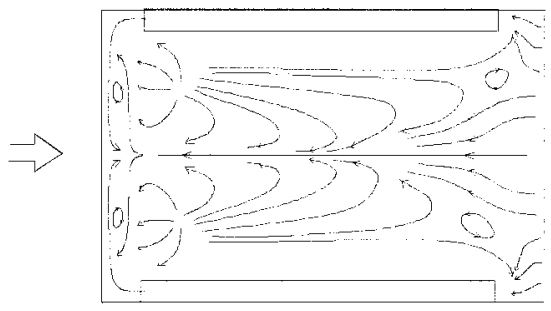

one tube along each side

Fig. 6. Surface flow patterns for a closed-type cavity with venting tubes.

transitional-open type, with the three-tube case being more effective as more air could be vented upstream.

The schlieren photograph is shown in Fig. 5. The extent of the expansion fan emanating from the leading edge is greatly reduced. The concentrated impingement and exit shock wave system over the cavity floor changes to that of spread compression wavelets. Based on the schlieren photograph, the sketch of the wave structures and flow field in the centerline plane of a typical closed-type cavity flow are also shown in Fig. 5. As the rear part of the flow fields lied outside of the observation window, the corresponding sketch was made based on physical understanding.

Oil flow visualization (Fig. 6) showed a surface streak line pattern that is completely different from that of the basic configuration. There was backflow not only inside the tubes, but also near the cavity centerline. Between the centerline and the tubes, the limiting streamline flowed downstream.

\subsection{Plate installed laterally over the cavity floor}

The effect of lateral plates at two locations over the cavity floor was tested. The plate had a thickness of $1 \mathrm{~mm}$ and heights of 2 and $4 \mathrm{~mm}$. The front and rear locations were 21 and $61 \mathrm{~mm}$ from the front face, respectively. Four combinations of plate heights and locations were tested. In the first case, a 4-mm-high plate was installed at the front location. It was hoped that the plate would intercept some amount of air from the separating shear layer, thereby increasing the pressure in the region ahead of it. In the second case, a plate was placed at the same location but it had a height of $2 \mathrm{~mm}$. In the third case, a 4-mm-high plate was installed at the rear location. It was hoped that a plate near the middle of the cavity would separate the closed-type long cavity into two short open-type cavities. In the fourth case, a 2-mm-high plate was placed at the rear location. The height may have been too small to separate the long cavity into two. However, it was hoped that the short plate might force the attached boundary 

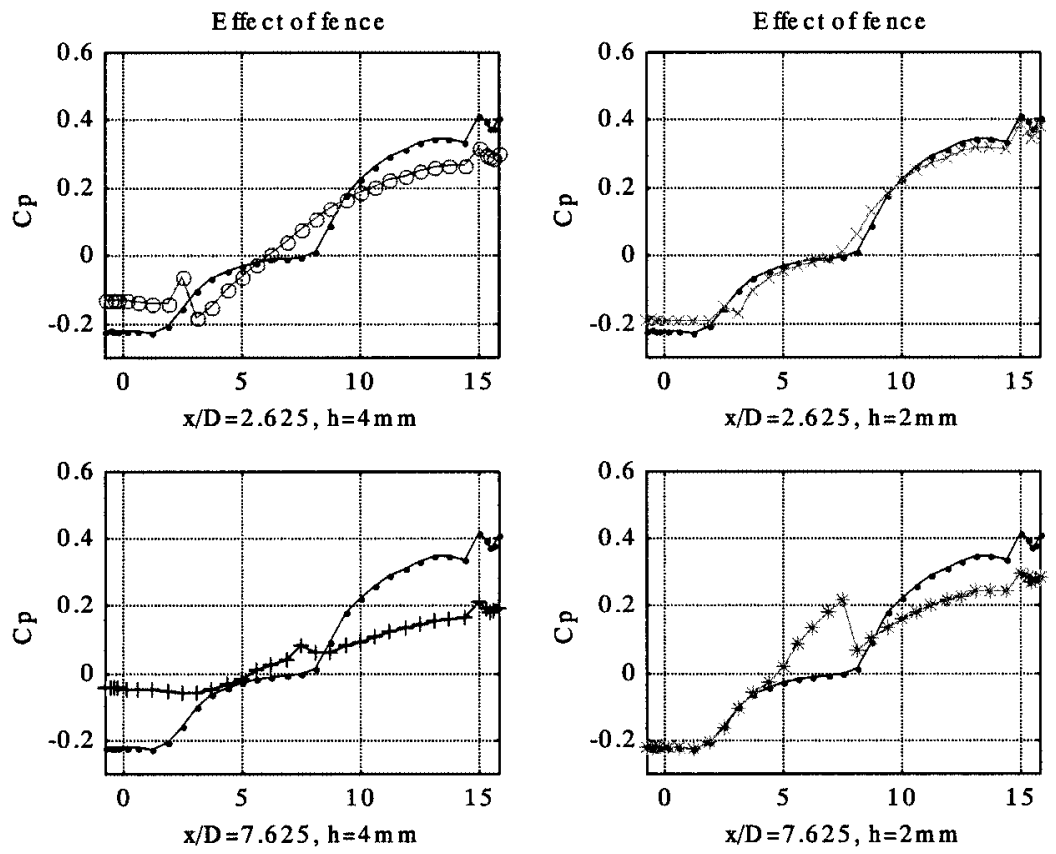

Fig. 7. Effects of baffle plate on pressure distribution.

layer near the mid-portion of the cavity to separate, thereby facilitating the formation of backflow.

Figure 7 compares the pressure coefficient distributions of the cavities with plate installed with that of the basic cavity. The following observations were made:

- The 4-mm-high plate installed near the middle of the cavity was most effective in changing the cavity flow to the transitional-open type. There was only a small kink near the location of the plate.

- The second most effective case was the 4-mm-high-plate installed near the front face. There was violent variation in pressure near the plate.

- For the 2-mm-high plate installed near the front face, the base pressure increased slightly and the recompression wake pressure decreased slightly, but the cavity flow type remained the same.

- For the 2-mm-high plate installed near the middle, the base pressure at the separation wake and subsequent pressure rise were nearly identical to that of the basic cavity, except that the pressure did not level off to a plateau in the middle portion of the cavity, but rather continued to rise nearly linearly up to the location of the plate. Behind the plate, there was an abrupt drop in pressure, followed by gradual rising. The pressure at the recompression wake was considerably lower than that of the basic cavity.

The schlieren photographs and sketch of the wave structures and flow field in the centerline plane for the cavity having the high plate at the middle are shown in Fig. 8. Compared with that of the basic cavity, the extent of the expansion fan emanating from the leading edge is greatly reduced. The concentrated impingement and exit shock wave system over the cavity floor changes to that of spread compression wavelets. A weak expansion fan can be observed to emanate
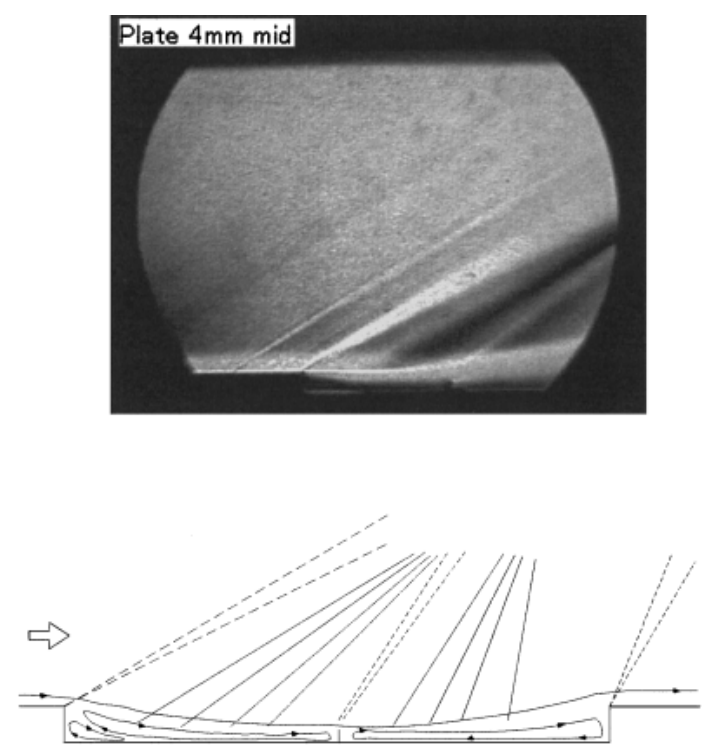

Fig. 8. Schlieren photograph and sketch of the wave structures and flow field in the centerline plane of a closed-type cavity with a baffle plate.

from above the baffle plate.

Sketches of the surface flow patterns for the 4-mm-high baffle plate placed at the front and middle positions of the cavity are shown in Fig. 9. For the plate placed at the middle, extensive back flow occurs in both shorter cavities. The streak line pattern in each cavity resembles that of opentype cavity flow. The flow is essentially two-dimensional throughout most of the cavities. For the plate at the front, streak lines pointing downstream indicate that secondary recirculation is induced by primary recirculation in the front cavity. In the rear cavity, the main flow reattaches on the floor and separates again before the rear face. 


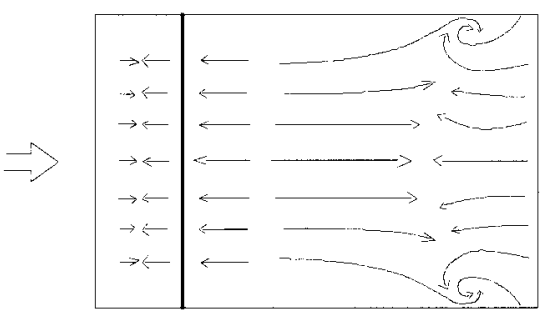

4mm-high-plate at front

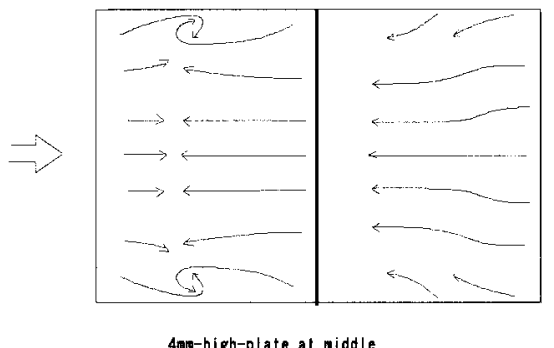

Fig. 9. Surface flow patterns for a closed-type cavity with a baffle plate.

As no effort was made in the present research to measure the effect of the control device on the drag of the cavity, it is not possible to draw any quantitative conclusion in this regard. There might be some concern that the strike of the backflow near the cavity floor on the baffle plate would increase the drag. However, the whole picture is that the occurrence of the backflow will squeeze the external flow outward, thereby decreasing its impact on the rear edge of the cavity. As the external flow has much higher dynamic pressure than that of recirculation inside the cavity, the total drag of the cavity should decrease considerably as the result of inserting the baffle plate.

\subsection{Downstream blowing along front corner}

Blowing from side-holes in a tube embedded at the front corner of the cavity sought to actively increase the pressure at the separation wake through introducing external air into it. Two cases with different flow rates were tested. In the first case, the tube was connected to the atmosphere. The resulting volume flow rate was about $5.17 \times 10^{-4} \mathrm{~m}^{3} / \mathrm{s}$ (31 SL/min). In the second case, the tube was connected to a high-pressure source in the wind tunnel. The volume flow rate, after conversion to the standard value, was about $3.3 \times 10^{-3} \mathrm{~m}^{3} / \mathrm{s}(200 \mathrm{SL} / \mathrm{min})$.

Figure 10 compares the pressure coefficient distribution of the cavity with a blowing tube installed with that of the basic cavity. There is essentially no change for the low-flow rate. For the high-flow rate, the base pressure increases slightly and the pressure distribution changes from that of closedtype to that of transitional-closed type.

A schlieren photograph shows essentially no change in wave pattern for the low-flow rate. For the high-flow rate, the distinct impingement and exit shocks in the basic cavity are somewhat smeared out and replaced with a spread compression region (Fig. 11).
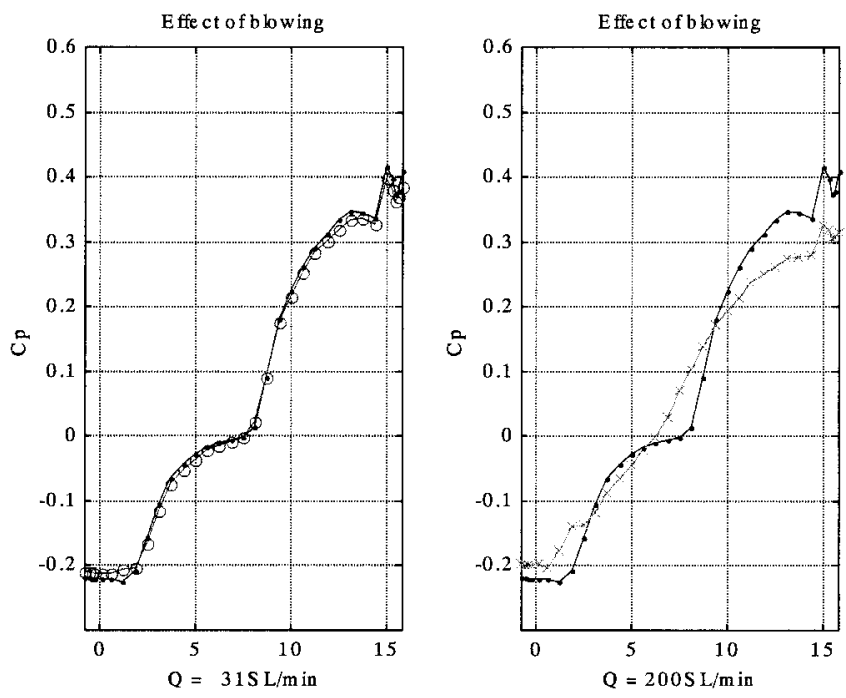

Fig. 10. Effects of external mass addition on pressure distribution through air injection.
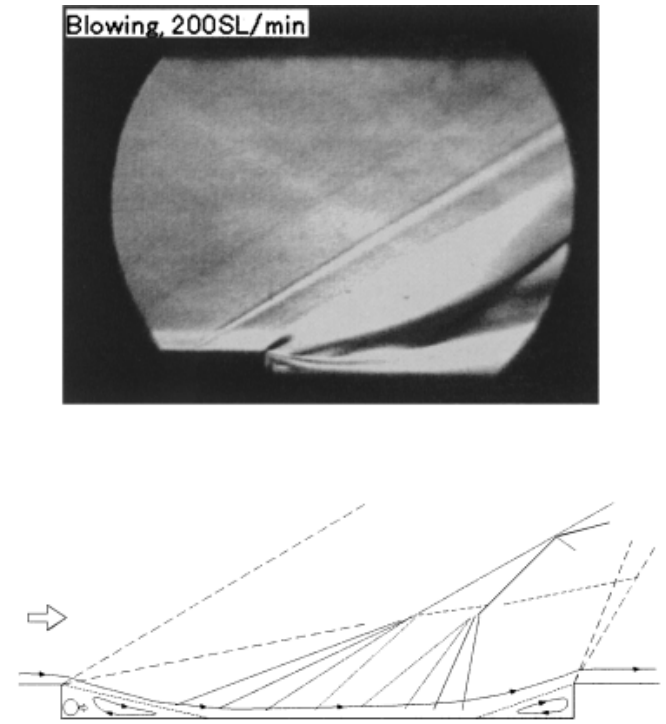

Fig. 11. Schlieren photograph and sketch of the wave structures and flow field in the centerline plane of a closed-type cavity with external mass addition.

To put the effect of blowing into perspective, the ratio of mass flow rate between the blowing and the external flow across an area equal to that of the cavity front face was calculated and was found to be about $2 \times 10^{-3}$ for the low-flow rate and $1.3 \times 10^{-2}$ for the high-flow rate. It is expected that blowing can be more effective if the air flow rate is further increased.

\subsection{Unsteady effects of the control devices}

The spectra of unsteady pressure signals indicated that new discrete pressure oscillations emerged when the 4-mmhigh plate was installed at the front location. The peak frequencies matched approximately the predicted values from Rossiter's ${ }^{9)}$ modified formula, the distance from the front wall to the plate being used as the cavity length. No discrete 
Table 1. Comparison of peak power and overall SPL for rearward-facing step and cavity flows (sampling frequency $20 \mathrm{kHz}$ ).

\begin{tabular}{ccccccccccc}
\hline Flow type & Step & $\begin{array}{c}\text { Cavity } \\
(L / D=15)\end{array}$ & $\begin{array}{c}\text { Tubes } \\
3+3\end{array}$ & $\begin{array}{c}\text { Tubes } \\
1+1\end{array}$ & $\begin{array}{c}4 \mathrm{~mm} \text { plate } \\
\text { middle }\end{array}$ & $\begin{array}{c}4 \mathrm{~mm} \text { plate } \\
\text { front }\end{array}$ & $\begin{array}{c}2 \mathrm{~mm} \text { plate } \\
\text { middle }\end{array}$ & $\begin{array}{c}2 \mathrm{~mm} \text { plate } \\
\text { front }\end{array}$ & $\begin{array}{c}\text { Flow rate } \\
31 \mathrm{SL} / \mathrm{min}\end{array}$ & $\begin{array}{c}\text { Flow rate } \\
200 \mathrm{SL} / \mathrm{min}\end{array}$ \\
\hline $\begin{array}{c}\text { Front sensor } \\
\quad \text { Peak power }\end{array}$ & 132 & 138 & - & - & 137 & 137 & 136 & 136 & 130 & 128 \\
$\quad$ Overall SPL & 158 & 164 & - & - & 163 & 164 & 164 & 164 & 158 & 157 \\
\hline Rear sensor & & & & & & & & & & 145 \\
$\quad$ Peak power & 127 & 153 & 132 & 138 & 140 & 143 & 145 & 143 & 145 \\
$\quad$ Overall SPL & 153 & 163 & 158 & 159 & 163 & 163 & 163 & 161 & 160 & 160 \\
\hline
\end{tabular}

pressure oscillations were detected in other cases or when other control devices were installed.

Table 1 compares the peak power and overall sound pressure level (SPL) at two locations near the foot of impingement and exit shock waves, for rearward-facing step, cavity of basic configuration and cavity with arrays of tubes, plate, or blowing device installed. The model for the rearwardfacing step is formed simply by removing the rear plate. The following observations were made:

- Cavity flows are much noisier than step flow. There is a considerable increase in both overall SPL and peak powers in cavity flow as compared to step flow. Due to the presence of exit shock wave in the cavity flow, the peak power at the rear sensor increases by about $26 \mathrm{~dB}$.

- Arrays of tubes along two sidewalls produce the greatest reduction of peak powers and overall SPL at the rear sensor.

- For the installation of plates, the peak power at the rear sensor is reduced by $8-13 \mathrm{~dB}$, while the peak power at the front sensor and overall SPL at both sensors remain essentially unchanged. Power spectra indicate that discrete pressure oscillations are induced only in the case of a 4-mm-high plate installed at the front location.

- Blowing air into the cavity front corner at a very-low flow rate is very effective for reducing the pressure oscillations in the cavity, although not effective for mitigating the adverse pressure gradient. It reduces the peak power at the front sensor by $8-10 \mathrm{~dB}$, and the overall SPL by $6-7 \mathrm{~dB}$. It reduces the peak power at the rear sensor by $8-14 \mathrm{~dB}$, and the overall SPL by $3 \mathrm{~dB}$.

\subsection{On the three-dimensionality of the flow field}

Surface flow patterns, as obtained through oilflow visualization, show predominantly two-dimensional features across the major portion of the cavity around the centerline for cavities with the baffle plate installed laterally. Some three-dimensional vortices are observed near the sidewalls of the cavities. Therefore, the pressure distribution measured near the centerline could be expected to represent the pressure field across the cavity floor well.

In contrast, the cavities with venting tubes embedded along the two sidewalls showed striking three-dimensional features across the whole floor. Although the schlieren photographs demonstrate a drastic weakening of the im- pingement and exit shock waves into that of compression wavelets, a more accurate and convincing estimation of the effects of the venting tubes could be obtained if pressure were measured at more points beside the centerline.

\section{Summary}

Three types of devices were tested for their effects in reducing the strong adverse pressure gradient in a closed-type cavity with a depth of $8 \mathrm{~mm}$ and length-to-depth ratio of 15 . The first type of control device consisted of longitudinally embedded arrays of tubes along the two sides of the cavity. It sought to move the high-pressure air at the recompression wake to the separation wake by creating a passage. The second type of control device consisting of installing a baffle plate laterally near the shock impingement line or the midpart the cavity floor. It aimed at changing the wave structure of the cavity flow through interfering with the reattaching or reattached boundary layer. The third type of control device tried to increase the base pressure by supplementing external fluid with downstream blowing through side-holes along a lateral tube placed at the front corner of the cavity.

Of the three types of control devices, the installation of tubes along the two sidewalls of the cavity was found to be the most effective in reducing the adverse pressure gradient along the cavity centerline. Of the four plate combinations installed laterally on the cavity floor, the 4-mm-high plate installed near the middle of the cavity was found to be most effective. The relative ineffectiveness of downstream blowing near the cavity front corner is believed to be a result of the low air-flow rate.

Unsteady pressure measurement at two locations for rearward-facing step, cavity of basic configuration and cavity with control device installed revealed that: (1) Cavity flow was much noisier than step flow; (2) Arrays of tubes along two sidewalls produced the greatest reduction in peak power and overall SPL at the rear location; (3) Discrete pressure oscillations were induced only when the 4-mm-high plate was installed at the front location; and (4) Blowing air into the cavity from the front corner, although ineffective in mitigating the adverse pressure gradient, is very effective for suppressing pressure oscillations in the cavity. 


\section{References}

1) Charwat, A. F., Roos, J. N., Dewey, F. C., Jr. and Hitz, J. A.: An Investigation of Separated Flows-Part I: The Pressure Field, J. Aerosp. Sci., 28 (1961), pp. 457-470.

2) Stallings, R. L., Jr. and Wilcox, F. J., Jr.: Experimental Cavity Pressure Distributions at Supersonic Speeds, NASA TP-2683, 1987.

3) Pereira, J. C. F. and Sousa, J. M. M.: Influence of Impingement Edge Geometry on Cavity Flow Oscillations, AIAA J., 32 (1994), pp. 17371740.

4) Heller, H. H. and Bliss, D. B.: Aerodynamically Induced Pressure Oscillations in Cavities-Physical Mechanisms and Suppression Concepts, AFFDL-TR-74-133, U.S. Air Force, Feb., 1975. (Available from DTIC as AD B002 701L)
5) Wilcox, F. J., Jr.: Experimental Investigation of Porous-Floor Effects on Cavity Flow Fields at Supersonic Speeds, NASA TP-3032, 1990.

6) Lamp, A. M. and Chokani, N.: Computation of Cavity Flows with Suppression Using Jet Blowing, J. Aircraft, 34 (1997), pp. 545-551.

7) Zhang, X., Chen, X.X. and Rona, A.: Attenuation of Cavity Flow Oscillation through Leading Edge Flow Control, J. Sound Vib., 221 (1999), pp. $23-47$.

8) Zhang, J. B.: Experimental and Computational Investigation of Supersonic Cavity Flows, Ph. D. Thesis, The University of Tokyo, Japan, Sept., 2000.

9) Rossiter, J. E.: Wind-Tunnel Experiments on the Flow over Rectangular Cavities at Subsonic and Transonic Speeds, R\&M No. 3438, British A.R.C., 1966. 